\title{
Leaf and floral heating in cold climates: do sub-Antarctic megaherbs resemble tropical alpine giants?
}

\author{
Lorna Little, ${ }^{1,2}$ Pernille Bronken Eidesen, ${ }^{2}$ Eike Müller, ${ }^{2}$ Katharine J.M. Dickinson ${ }^{1}$ \& Janice M. Lord ${ }^{1}$ \\ 1 Department of Botany, University of Otago, PO Box 56, 9054 Dunedin, New Zealand \\ ${ }^{2}$ Arctic Biology Department, University Centre in Svalbard, PO Box 156, NO-9171 Longyearbyen, Norway
}

\section{Keywords}

Campbell Island; flower colour; thermal

imaging; Pleurophyllum speciosum.

\section{Correspondence}

Lorna Little, Department of Botany, University of Otago, PO Box 56, 9054 Dunedin, New Zealand.

E-mail: little.lorna5@gmail.com

\begin{abstract}
High latitude and altitude floras are characterized by low-statured, small, wind-pollinated plants, which mainly reproduce by self-pollination or asexual reproduction. However, at odds with this are some sub-Antarctic islands that have plant species with giant growth forms and large, brightly coloured flowers which require insect visitation for pollination. The size, colour and shape of the inflorescences and leaves of these megaherbs suggest thermal benefits similar to giant tropical alpine plants of equatorial Africa, South America and Hawaii. We evaluated whether heating occurs in sub-Antarctic megaherbs, and to what extent it is related to environmental variables. We measured leaf and inflorescence temperature in six sub-Antarctic megaherb species on Campbell Island, latitude $52.3^{\circ} \mathrm{S}$, New Zealand Biological Region. Using thermal imaging techniques, in combination with measurement of solar radiation, ambient air temperature, wind speed, wind chill and humidity, we assessed environmental influences on leaf and floral heating. We found that leaf and inflorescence temperatures of all megaherbs were higher than simultaneously measured ambient temperatures. Greatest heating was seen in Pleurophyllum speciosum, with observed leaves $9^{\circ} \mathrm{C}$ higher, and inflorescences nearly $11^{\circ} \mathrm{C}$ higher, than ambient temperature. Heating was highly correlated with brief, unpredictable periods of solar radiation, and occurred most rapidly in species with hairy, corrugated leaves and darkly pigmented, densely packed inflorescences. This is the first evidence that floral and leaf heating occurs in sub-Antarctic megaherbs, and suggests that leaf hairiness, flower colour and shape could provide thermal benefits like those seen in tropical alpine megaherbs.
\end{abstract}

To access the supplementary material for this article, please see the supplementary files under Article Tools, online.
Plants at high latitudes and altitudes experience short growing seasons, low mean annual temperatures, strong winds and large annual and diurnal fluctuations in solar radiation and temperature (Chapin \& Körner 1995; Körner 2003). Many features typical of these floras, such as flower and leaf orientation, and leaf thickness and hairiness, are thought to control internal temperatures so as to speed up metabolic processes while minimizing tissue damage (Kevan 1975; Bingham \& Ort 1998; Choler 2005). Quick heating and retention of heat by photosynthetic and reproductive plant parts could be considered an important adaptation in cold climates as it can increase the number of growing degree-days and thus facilitate successful reproduction (Rejskova et al. 2010; Song et al. 2013; Weijers et al. 2013). However, the most obvious and general adaptation to the severe high latitude and altitude environments is a reduction in plant size and height, which minimizes wind chill, abrasion and desiccation (Billings \& Mooney 1968).

The sub-Antarctic, generally defined as the region between the latitudes of $40^{\circ}$ and $60^{\circ}$ South, is characterized by the presence of the Antarctic Polar Frontal Zone, 


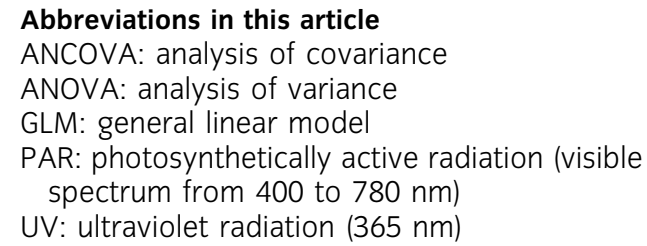

year-round cold temperatures (mean temperature of $6.8^{\circ} \mathrm{C}$ ), strong winds $\left(70 \%\right.$ of days with winds above $7.5 \mathrm{~m} \mathrm{~s}^{-1}$ ), low sunshine hours per year (640 h of sunshine per annum) and frequent cloud cover, with little seasonal variation (Meurk, Fogg, Thomson et al. 1994; Bergstrom \& Chown 1999). A number of the leaf and flower features typical of the flora of the sub-Antarctic region show correlations with general high altitude or latitude plant features, such as rosette forming plant species and hairy leaves (Troll 1960; Mark et al. 2000). A major exception is the large size of some species, with average shoot dry weights in the range of 180-220 g and average fresh:dry weight ratios of up to 10.13 g (Nicholls \& Rapson 1999). These endemic subAntarctic megaherbs are characterized by giant leaf size and deeply pigmented flowers (Peat 2006), features that have most likely evolved in situ (Wagstaff et al. 2011).

These megaherbs resemble the giant, rosette growth forms seen in tropical alpine regions of Africa, South America and Hawaii which possess thick, hairy leaves, which are massive and sometimes tightly arranged (Smith \& Young 1987; Nicholls \& Rapson 1999). In tropical alpine species, these features are proposed to mitigate the stressors of high radiation input and high diurnal temperature fluctuations that characterize high altitude regions (Hedberg \& Hedberg 1979; Smith \& Young 1987). The large, hairy leaves of sub-Antarctic megaherbs may provide a similar thermal benefit in the sub-Antarctic climate (Wardle 1991; Peat 2006).

Many examples of convergent evolution in plants are known from geographically distinct, but environmentally similar, biomes around the world (Halloy \& Mark 1996; Reich et al. 1997). The climate and environment of the sub-Antarctic islands of New Zealand have some similarities to tropical alpine regions (Mark et al. 2000). Both tropical alpine and sub-Antarctic regions experience low variation in mean annual temperature (e.g., mean temperature in the tropical high Andes varies by $5.5^{\circ} \mathrm{C}$ during four summer months, sub-Antarctic Macquarie Island mean temperature varies by $4{ }^{\circ} \mathrm{C}$ throughout the year), but can have high fluctuations in temperature and available sunshine diurnally (Troll 1960; Pendlebury \& Barnes-Keoghan 2007). In tropical alpine regions, temperature provides a strong selective pressure on plant traits and the warmest four to five hours in a day are critically important to plant functioning (Mark et al.
2000). Convergent evolution of giant rosette growth forms and leaf and floral traits that appear to insulate flowers and young growing leaves has been observed in the Himalayas and tropical alpine regions such as in the equatorial Andes, Kenya and Hawaii (Young 1984; Meinzer \& Goldstein 1985; Miller 1986). For example, brightly coloured bracts improve reproduction in the giant Rheum nobile in the Himalayas, not only by attracting pollinators but also by facilitating development of fruit because of higher heat retention (Song et al. 2013). Leaf and floral hairiness of giant herbs in the Himalayas, Hawaii and equatorial Andes has been shown to increase temperatures at the leaf surface and inside the flower by increasing the boundary layer and reflecting long wave radiation into the centre of the giant rosette (Miller 1986; Meinzer et al. 1994; Yang et al. 2008). Further, it has recently been determined that temperatures inside continental alpine flowers are dependent on solar radiation, with size and density of the floral unit being significant co-factors (Dietrich \& Körner 2014). Giant herbaceous species in the tropical alpine regions have similar plant traits across continental regions, and are an example of functional convergent evolution (Smith \& Young 1987; Rundel et al. 1994; Givnish 2010). The giant megaherbs of the sub-Antarctic islands, which share many traits with these tropical species, could be a further instance of convergent evolution.

On oceanic, sub-Antarctic Campbell Island $\left(52^{\circ} 33 \mathrm{~S}\right.$, $\left.169^{\circ} 16 \mathrm{E}\right)$, a diversity of megaherb species differing in leaf size and surface features as well as flower colour grow intermixed in herbfields together with tussockforming grasses, smaller herbaceous species and some shrubs. Thus Campbell Island provides an opportunity to examine spatial and temporal patterns in plant temperature for a range of species under natural field conditions. Here we present, for the first time, temperature information from inflorescences and leaves of the remarkable giant herbs from the sub-Antarctic region, and investigate the extent to which inflorescence and leaf temperatures are influenced by various microclimatic conditions, including solar radiation. We expect that leaf and inflorescence temperatures will be strongly influenced by microclimatic conditions, but that the degree of heating of inflorescences and leaves should also be influenced by degree of pigmentation, hairiness and denser arrangements of leaves and inflorescences. Also, as plant energy exchange is usually more affected by solar radiation than by conduction or convection (e.g., Monteith \& Unsworth 2013), under sunlight conditions, we would expect a closer relationship between inflorescence or leaf surface temperature and solar radiation than with factors such as ambient air temperature. 


\section{Materials and methods}

The study was conducted from 6 to 10 December 2010 (during the austral summer) on Campbell Island, which is situated in the Southern Ocean. Campbell Island is the southernmost of New Zealand's sub-Antarctic islands, and supports a diverse flora as is outlined in its World Heritage Status declaration (UNESCO 1992-2014).

\section{Thermal image data compared with ambient air temperatures}

Floral heating in six, now common, megaherb species (Meurk, Foggo \& Wilson 1994) was investigated by thermal imaging (Table 1). These species were similar in size (Moore \& Edgar 1976; Allan 1982; Nicholls \& Rapson 1999), while their flower colour varied from dark purple (Asteraceae; Pleurophyllum speciosum, and P. criniferum) to light pink (Apiaceae; Anisotome latifolia) and yellow (Asphodeloideae; Bulbinella rossii, Araliaceae; Stilbocarpa polaris) (Table 1). Thermal images were taken using a Fluke T120 Thermal Imager. Thermal images of the entire plant were taken to match a digital photograph. Ambient air temperatures were measured while the thermal image was being taken.

Images were processed by InsideIR Image Explorer software (Fluke Corporation) to obtain the maximum, minimum and average temperature of each inflorescence. The temperature values were found by drawing an outline around the inflorescences and setting markers within the outline using the Image Explorer. The minimum and maximum temperatures within the inflorescences were recorded. Temperatures were tabulated with corresponding measures of ambient temperature to calculate the difference between inflorescences temperature and ambient temperature. Maximum inflorescence heating was calculated as maximum inflorescences temperaturecorresponding ambient temperature.

Mean differences between minimum and maximum inflorescence temperatures and ambient temperatures were evaluated for each species by paired $t$-tests. ANOVA and Tukey's pairwise post-hoc tests were used to evaluate differences in mean maximum inflorescence heating among species. The images were inspected to describe temperature differences.

\section{Temporal thermal probe data related to environmental variables}

For four of the six species, inflorescence temperature and leaf surface temperature measurements were also taken using a thermal probe (Fluke 51 II digital thermometer with $80 \mathrm{PK}-1$ bead probe; accurate to $0.01^{\circ} \mathrm{C}$ ) every 10 (B. rossii), 15 (P. criniferum) and $30 \mathrm{~min}$ (P. speciosum, S. polaris) during a "time course" from mid-morning to midafternoon (Table 3). Per time point, one measurement was made per inflorescence or leaf. The internal inflorescence temperature was measured by inserting the probe into the centre of the top floret of the inflorescence and leaf temperature was measured by holding the probe onto the surface of the centre of the uppermost, mature leaf. In P. speciosum, the probe was placed on the sunny side of the leaf ridges. Because of logistical constraints, only one plant per species was used for the time-course measurements and for each plant, one inflorescence and leaf was measured multiple times. All measurements for a plant species were conducted over the course of a single day. As the probe potentially could be affected by both contact with the leaf surface and by absorption of radiation from the sunlight, thermal pictures were taken regularly during the probe measurements, and image temperatures were compared with probe data to validate the probe measurements.

Table 1 Locality and species descriptions of six megaherb species investigated for relations among plant structures, plant colours and temperature from Campbell Island. Leaf and floral characteristics follow descriptions by Allan (1982) and Moore \& Edgar (1976).

\begin{tabular}{|c|c|c|c|c|}
\hline Species & Locality & Leaf type and surface & Leaf width, length & Flower colour \\
\hline $\begin{array}{l}\text { Pleurophyllum } \\
\text { speciosum }\end{array}$ & $\begin{array}{l}\text { Megaherb field on Col Lyall ridge, } \\
\text { ca. } 250 \mathrm{~m} \text { a.s.l. }\end{array}$ & $\begin{array}{l}\text { Orbicular, corrugated, } \\
\text { hairy }\end{array}$ & $\begin{array}{l}\text { Up to } 45 \mathrm{~cm} \text { wide, } \\
25 \mathrm{~cm} \text { length }\end{array}$ & $\begin{array}{l}\text { Dark purple disc, lighter ray } \\
\text { florets }\end{array}$ \\
\hline Stilbocarpa polaris & $\begin{array}{l}\text { Megaherb field on Col Lyall ridge, } \\
\text { ca. } 250 \mathrm{~m} \text { a.s.l. }\end{array}$ & Orbicular and hairy & $\begin{array}{l}\text { Up to } 30 \mathrm{~cm} \text { wide, } \\
20 \mathrm{~cm} \text { length }\end{array}$ & Greenish yellow \\
\hline $\begin{array}{l}\text { Pleurophyllum } \\
\text { criniferum }\end{array}$ & $\begin{array}{l}\text { Meteorological Service Base, coastal, } \\
\text { ca. } 20 \mathrm{~m} \text { a.s.l. }\end{array}$ & Ovate, flat, downy & $\begin{array}{l}\text { Up to } 45 \mathrm{~cm} \text { wide, } \\
1 \mathrm{~m} \text { length }\end{array}$ & Dark red-purple \\
\hline Bulbinella rossii & $\begin{array}{l}\text { Meteorological Service Base, coastal, } \\
\text { ca. } 20 \mathrm{~m} \text { a.s.l. }\end{array}$ & Strap-like, smooth & $\begin{array}{l}\text { Up to } 6 \mathrm{~cm} \text { wide, } \\
40 \mathrm{~cm} \text { length }\end{array}$ & $\begin{array}{l}\text { Orange yellow-greenish } \\
\text { yellow }\end{array}$ \\
\hline Pleurophyllum hookeri & $\begin{array}{l}\text { Beside the boardwalk to Col Lyall, } \\
\text { ca. } 180 \mathrm{~m} \text { a.s.l. }\end{array}$ & Elliptic, flat, downy & $\begin{array}{l}\text { Up to } 7 \mathrm{~cm} \text { wide, } \\
35 \mathrm{~cm} \text { length }\end{array}$ & Dark red-purple \\
\hline Anisotome latifolia & $\begin{array}{l}\text { Megaherb field on Col Lyall ridge, } \\
\text { ca. } 250 \text { m a.s.l. }\end{array}$ & $\begin{array}{l}\text { Highly divided, smooth } \\
\text { and flat }\end{array}$ & $\begin{array}{l}\text { Up to } 25 \mathrm{~cm} \text { wide, } \\
35 \mathrm{~cm} \text { length }\end{array}$ & Various shades of pink \\
\hline
\end{tabular}


For each probe temperature measurement, five environmental variables were measured at the same height above ground as the target plant. Ambient air temperature, wind speed and wind chill were measured using a Kestrel 3000 Handheld Weather meter and noted after each thermal recording. PAR was measured using a LiCor Light Meter, measurements being averaged over $15 \mathrm{~s}$, while UV radiation (365 nm) was measured using a RS365 Radiometer (UVItec Ltd.).

\section{Statistical analyses of temporal data}

In order to establish which environmental factors influenced heating in megaherbs, leaf and inflorescence temperatures from the time-course data sets were compared with environmental measurements. Spearman's Rank correlation was used to test correlations between all measured environmental variables. The influence of five predictor variables (air temperature, PAR, species, wind and humidity) upon floral and leaf temperature (response variables) was tested with a GLM specified for normal error distributions for each response variable. The initial models were the most complex ones with all interactions included (Supplementary Table S1). Models were simplified through stepwise removal of interactions between predictors, and if possible, removing irrelevant predictor variables. In addition to evaluating the Akaike information criterion, models were sequentially compared using ANOVAs, and further simplified if no significant difference in explanatory power was observed. The fit of the final models was evaluated with the diagnostic plot function in $\mathrm{R}$ software, version 2.16 ( $\mathrm{R}$ Development Core Team 2012).

For each of the four species with time-course data (Table 3), GLMs were used to compare the slopes of the leaf temperature, the inflorescence temperature and the ambient temperature in response to PAR. The model structure was equivalent to an ANCOVA, analysing the observed temperature in three categories (inflorescence, leaf and ambient) in response to PAR. For the species
P. criniferum, we chose to omit the sample values measured at $10.30 \mathrm{am}$ as they were categorized as highly divergent in the diagnostic plots of the model.

Although they are all megaherbs, the species included represent different entities with different attributes and were measured under slightly different conditions. To be able to evaluate each single species in more detail, linear regression analyses were done on each species separately, using inflorescence temperature or inflorescence heating (inflorescences temperature-ambient temperature) as response variables. As predictor variables we chose ambient temperature and PAR based on the combined analyses described above. Additionally, the mean difference between measured inflorescence temperatures and ambient temperatures were evaluated for each species by paired sample $t$-test. All analyses were run using $\mathrm{R}$, version 2.16 (R Development Core Team 2012).

\section{Results}

\section{Thermal image data compared with ambient air temperature}

Data based on the 52 thermal images collected clearly showed that inflorescences of all six megaherb species were warmer than ambient temperatures (Table 2). The maximum inflorescence temperatures were significantly higher than ambient temperatures for all species, except in Pleurophyllum criniferum, which also had the smallest sample size (Table 2). The greatest increases were registered for Pleurophyllum speciosum and P. hookeri, which both have dark-coloured inflorescences. The ANOVA analyses comparing mean inflorescence heating suggested significant differences among species, although the Tukey's pairwise comparison showed that the difference was only significant between $P$. hookeri, that showed the strongest response, and P. criniferum, that showed the weakest response.

Inspection of the thermal images revealed that different floral parts showed significantly different degrees of

Table 2 Six megaherb species from Campbell Island investigated by thermal imaging. $N$ indicates number of thermal images collected from different plants, except for Pleurophyllum speciosum and $P$. hookeri, which had multiple images taken of the same plant. Mean ambient temperatures and mean minimum and maximum inflorescence temperatures registered in thermal images are given \pm standard deviation. Significance levels between mean ambient temperature and mean inflorescence temperatures were tested by paired $t$-tests ( $* \star * P<0.001,{ }^{\star} * P<0.01,{ }^{\star} P<0.05$ ). Floral heating effects are given as mean maximum increases in flower temperature above the simultaneously measured air temperature \pm standard deviation.

\begin{tabular}{|c|c|c|c|c|c|}
\hline Species & $N$ & Mean ambient temp. $\left({ }^{\circ} \mathrm{C}\right)$ & Mean min. flower temp. $\left({ }^{\circ} \mathrm{C}\right)$ & Mean max. flower temp. $\left({ }^{\circ} \mathrm{C}\right)$ & Mean flower heating $\left({ }^{\circ} \mathrm{C}\right)$ \\
\hline Pleurophyllum speciosum & 8 & $7.13 \pm 0.10$ & $8.96 \pm 2.33^{*}$ & $8.96 \pm 5.38 * *$ & $8.68 \pm 5.33$ \\
\hline Stilbocarpa polaris & 7 & $7.4 \pm 0.38$ & $9.14 \pm 2.74$ & $9.14 \pm 4.00 *$ & $4.5 \pm 3.70$ \\
\hline Bulbinella rossii & 22 & $11.57 \pm 0.91$ & $13.32 \pm 1.89 * \star \star$ & $13.32 \pm 3.18^{\star \star \star}$ & $6.96 \pm 0.57$ \\
\hline Pleurophyllum hookeri & 5 & $11.08 \pm 2.63$ & $15.40 \pm 2.25^{\star * *}$ & $20.70 \pm 2.67 * * *$ & $9.62 \pm 0.91$ \\
\hline Anisotome latifolia & 5 & $12.50 \pm 0$ & $12.58 \pm 0.92^{\star \star \star}$ & $17.96 \pm 1.94^{\star \star \star}$ & $5.46 \pm 1.94$ \\
\hline
\end{tabular}


Table 3 Summary of floral and leaf heating effects of four megaherb species measured by thermal probe measurements at Campbell Island. One plant per species was measured over time. $N$ indicates number of thermal measurements per plant. Floral and leaf heating effects are given as mean increases in inflorescence and leaf temperature above the simultaneously measured air temperature. Significant difference tested by paired $t$-tests $(\star \star \star P<0.001, \star \star P<0.01, * P<0.05)$.

\begin{tabular}{|c|c|c|c|c|c|c|c|}
\hline Species & Sampling date & Duration of time course & $N$ & Mean air temperature & Mean PAR & $\begin{array}{l}\text { Mean flower } \\
\text { heating }\left({ }^{\circ} \mathrm{C}\right)\end{array}$ & $\begin{array}{l}\text { Mean leaf } \\
\text { heating }\left({ }^{\circ} \mathrm{C}\right)\end{array}$ \\
\hline Pleurophyllum speciosum & 1 December 2010 & 4 h $(09: 30-15: 30)$ & 13 & $7.97 \pm 0.96$ & $858 \pm 416$ & $3.60 \pm 3.52^{\star \star \star}$ & $2.5 \pm 2.72^{\star \star}$ \\
\hline Pleurophyllum criniferum & 6 December 2010 & 4 h (10:30-14:30) & 13 & $9.15 \pm 1.74$ & $485 \pm 319$ & $1.76 \pm 1.09 * \star \star$ & $0.57 \pm 0.65^{\star \star}$ \\
\hline Bulbinella rossii & 3 December 2010 & 2 h, $20 \min (10: 10-12: 30)$ & 15 & $10.16 \pm 0.62$ & $979 \pm 375$ & $0.60 \pm 0.84^{\star}$ & $0.94 \pm 0.85^{\star \star \star}$ \\
\hline
\end{tabular}

heating. For example, in thermal images of P. speciosum, the dark purple disc florets appeared much warmer (up to $9^{\circ} \mathrm{C}$ ) than the light purple ray florets (Fig. la). Further, the inflorescences of Bulbinella rossii exhibited the most floral heating towards the top of the spike where young, freshly opened inflorescences were present (Fig. lb). Inspection of thermal images suggested that the leaves had similar temperature trends as the inflorescences. Species with the warmest inflorescences also seemed to have the warmest leaves. The hairy leaves of Pleurophyllum species, especially the large corrugated leaves of P. speciosum, were very warm compared to background vegetation, as were the corrugated leaves of Stilbocarpa polaris (Fig. la, b, d); however, the glabrous leaves of $B$. rossii showed minimal heating (Fig. 1c). These observations were also confirmed by the analyses of thermal probe measurements.

\section{Temporal thermal probe data related to environmental variables}

Fifty-four sets of thermal probe measurements were collected for the four megaherb species included in time-course measurements. Temperatures read from thermal images taken in parallel with thermal probe measurements showed congruent and similar results (correlation coefficient $R=0.75, P<0.001, n=15$ ), and we felt confident that our probe data reflected actual plant surface temperatures. Overall, our probe data confirmed the results based on thermal imaging (Table 3).

Air temperature was found to have a significant influence on floral temperatures in all species (Supplementary Tables S2, S3, S4). UV radiation and wind chill were removed as predictor variables in further analyses as they were highly correlated with PAR and ambient temperature respectively (data not shown). During the model simplification, wind speed and humidity were also excluded as they did not explain a significant amount of variability in the response variables. The best fitting GLM for inflorescence temperature across all species showed that air temperature was a major explanatory factor, while the influence of PAR varied among species (Supplementary Table S2). PAR had a significant influence on the inflorescence temperature of $P$. speciosum, indicating that floral temperature of this species increased more under high PAR levels than in other species.

Air temperature was also found to have a significant influence on leaf temperature for all species (Supplementary Table S3). There was a significant interaction between leaf temperature of $P$. speciosum and PAR, showing that leaf temperature in this species increased proportionately more under high PAR levels compared with other species. A similar interaction between $S$. polaris and PAR was marginally non-significant.

Furthermore, as temperature and PAR were significantly correlated $\left(R_{S}=0.49, P=0.0002\right)$, the model approach above was restricted to identify the main explanatory variables and whether species responded in a similar pattern. As they did not (thermal pictures taken at high PAR indicated strong responses for some species), we analysed the data separately for each species, with an emphasis on their response to PAR.

Congruent with results from the GLMs, regression analyses per species showed that $P$. speciosum had the strongest response to PAR; while ambient temperatures showed an increase of only $0.17^{\circ} \mathrm{C}$ in response to a PAR increase of $100 \mu \mathrm{mol} \mathrm{m}{ }^{-2} \mathrm{~s}^{-1}$, inflorescences temperatures increased by $0.93^{\circ} \mathrm{C}$ and leaves by $0.57^{\circ} \mathrm{C}$ (Fig. 2a). The regression coefficients for inflorescence temperature on PAR were greater than for inflorescence temperature on air temperature, and the increases in inflorescence temperature were also significantly different from those for leaves.

In $S$. polaris, both leaves and inflorescences responded almost identically to increased PAR (Fig. 2b), and both were significantly different from the increase in the ambient temperature (both leaves and inflorescences ca. $0.4^{\circ} \mathrm{C}$ per $100 \mu \mathrm{mol} \mathrm{m} \mathrm{m}^{-2} \mathrm{~s}^{-1}$ ), but no significant differences were found between leaves and inflorescences.

In $P$. criniferum, the regression slopes of the inflorescence and leaf temperatures on PAR were similar and not significantly different from those on ambient temperature; however, the intercepts were significant different (Fig. 2c). At any given PAR value, the inflorescence temperatures showed a rather constant increase (ca. $2^{\circ} \mathrm{C}$ ) above the ambient temperature. The leaves of 
(a)

(b)
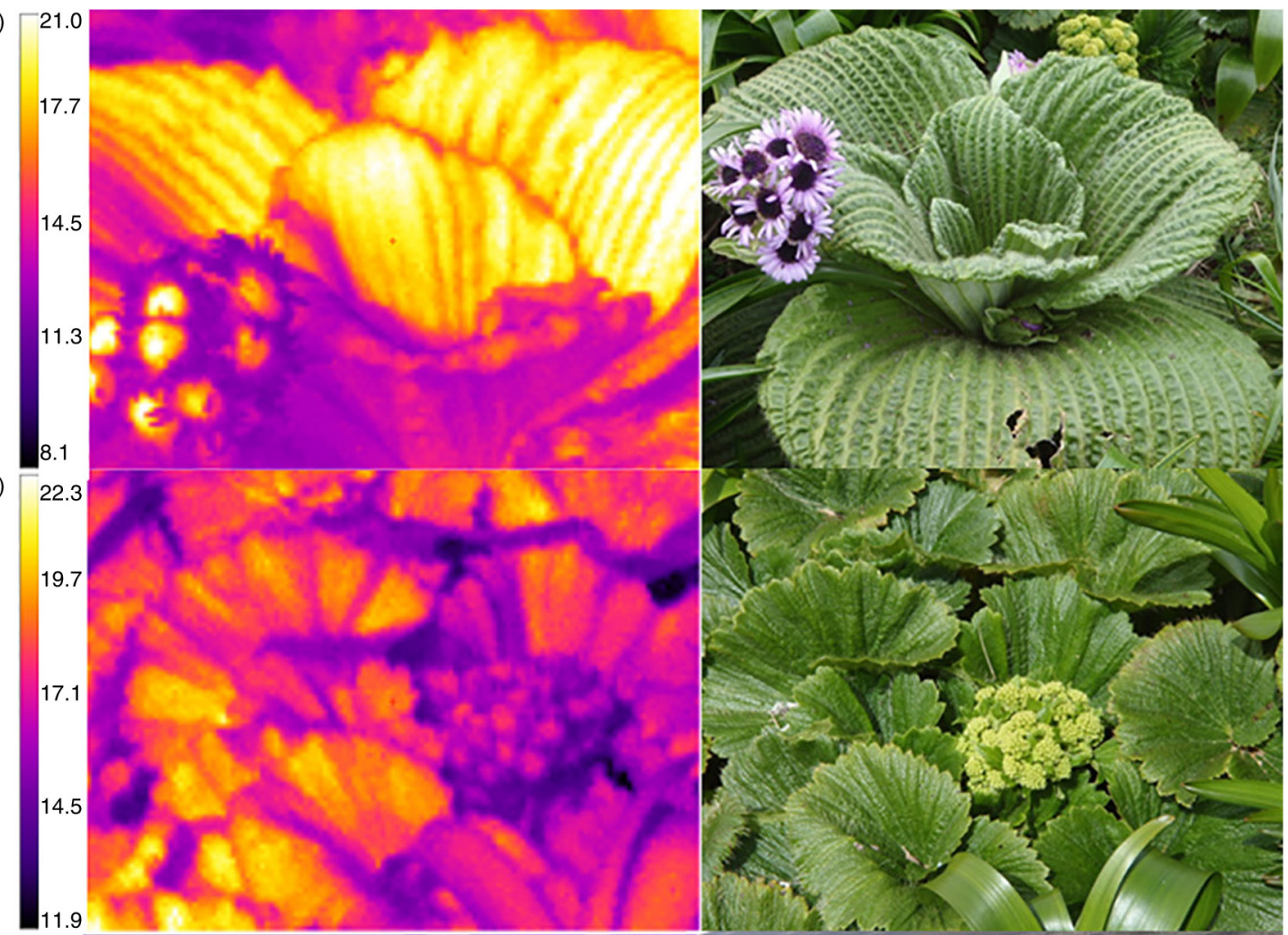

(c)
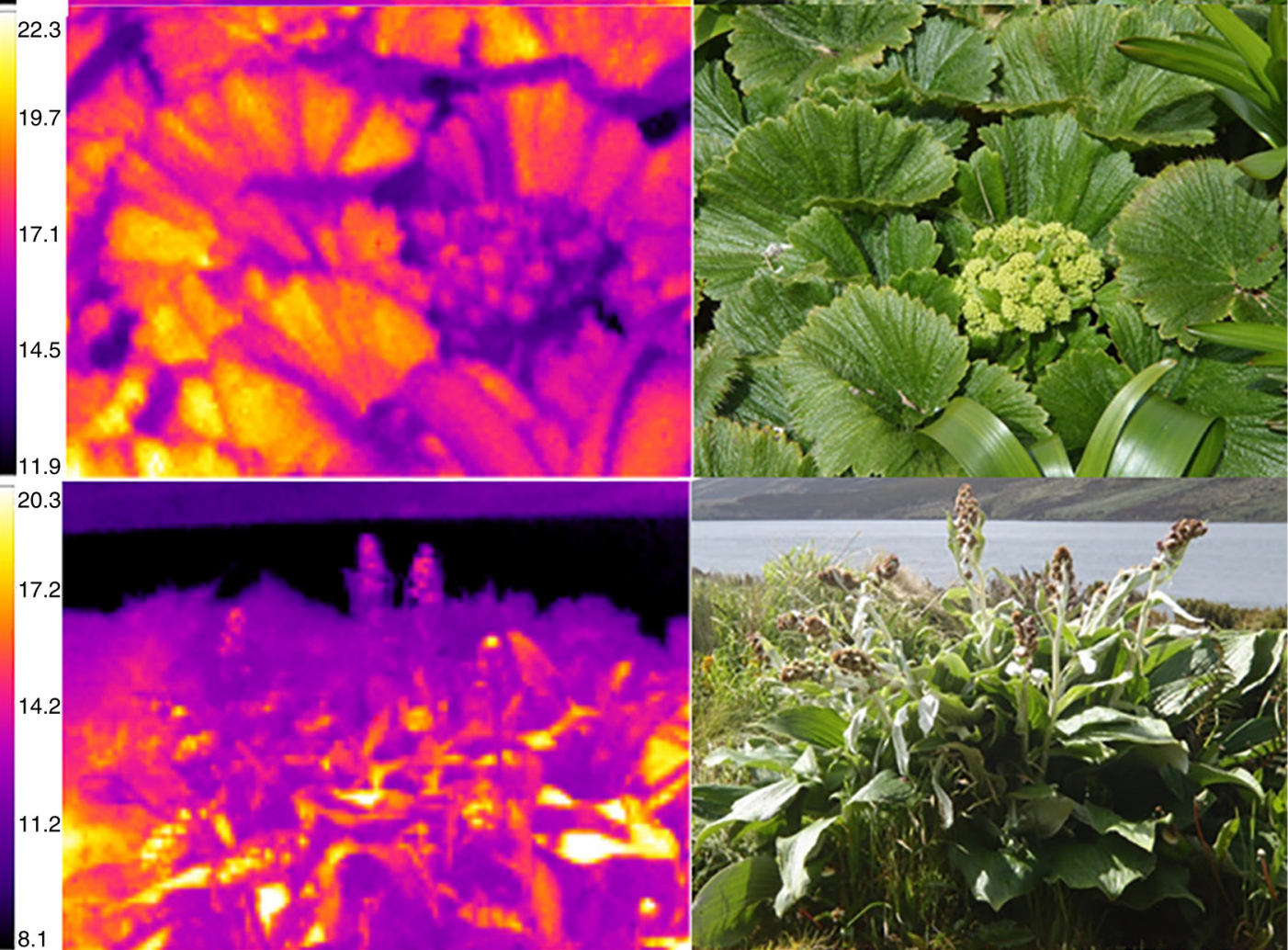

d)

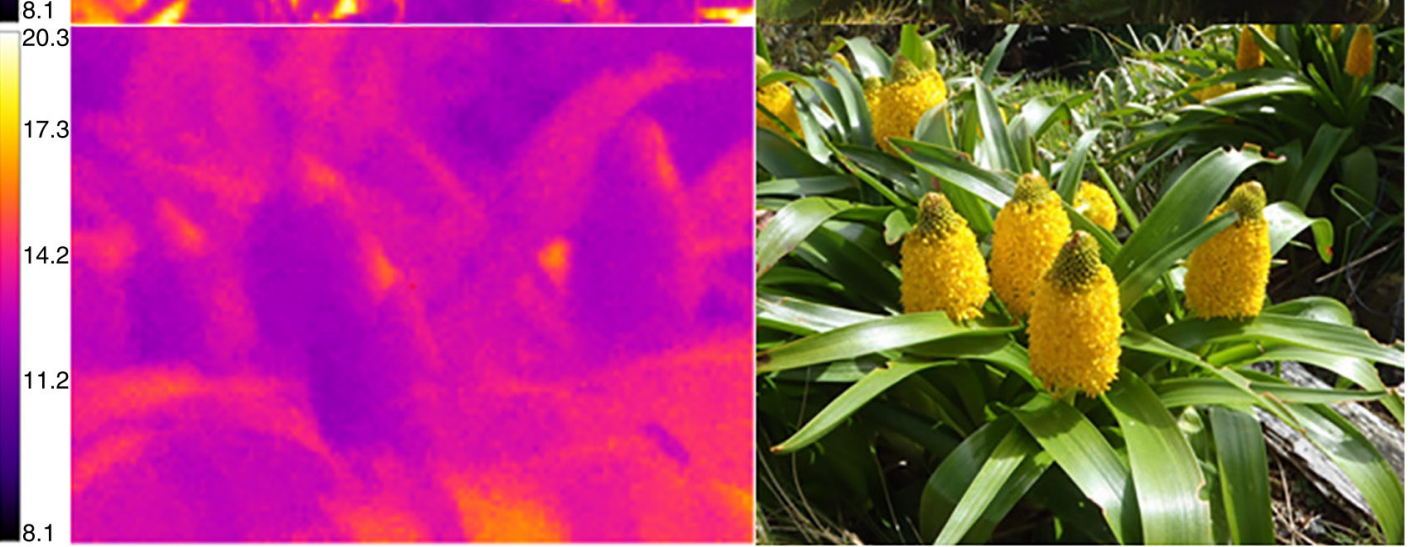

Fig. 1 Thermal images (left) and corresponding digital images (right) of the megaherb species included in time-course measurements. (a) Pleurophyllum speciosum, (b) Stilbocarpa polaris, (c) Pleurophyllum criniferum, (d) Bulbinella rossii. 

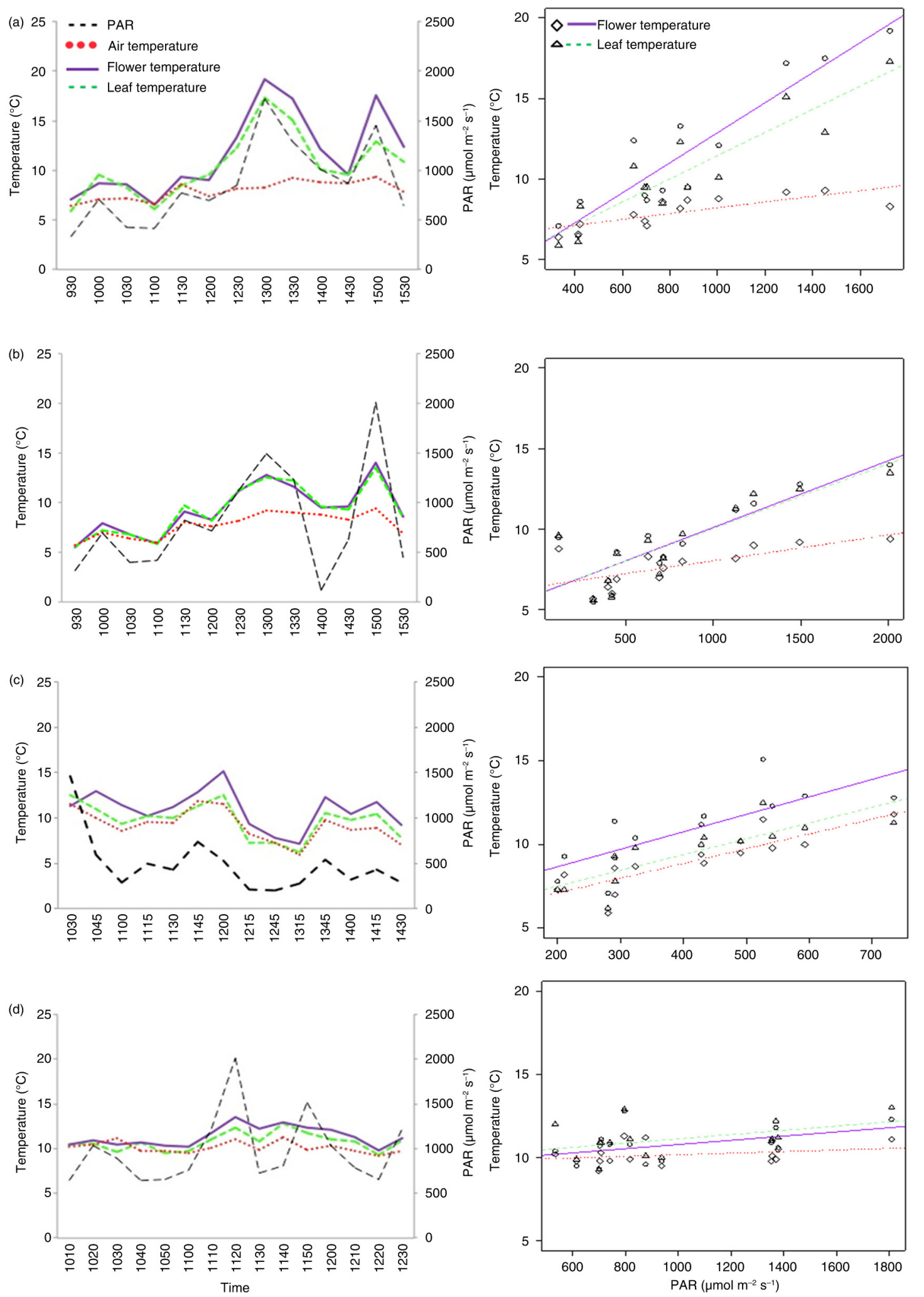

Fig. 2 Time courses (left) and linear model regression (right) of time-course data displaying relationship between inflorescence temperature, leaf temperature, air temperature and PAR in megaherb species for (a) Pleurophyllum speciosum, (b) Stilbocarpa polaris, (c) Pleurophyllum criniferum and (d) Bulbinella rossii. Linear model regression (right) of time-course data displaying relationship between flower temperature and PAR in megaherb species. Only (a) P. speciosum and (b) S. polaris were measured on the same day (Table 3). 
P. criniferum showed only a minimal response $\left(0.5^{\circ} \mathrm{C}\right)$ and were not significant warmer than the ambient air.

Bulbinella rossii showed the weakest response to increasing PAR. Inflorescence temperatures in $B$. rossii were not significantly different from ambient temperatures. Leaf temperatures were about $0.9^{\circ} \mathrm{C}$ warmer than the ambient temperatures, but showed low and similar responses to both PAR and air temperatures $\left(0.1^{\circ} \mathrm{C}\right.$ per $100 \mu \mathrm{mol} \mathrm{m}{ }^{-2} \mathrm{~s}^{-1}$ ).

Overall, both inflorescence and leaf temperatures of P. speciosum was better predicted by PAR than by ambient temperatures (Supplementary Table S5). However, all other species correlated better with ambient temperatures.

\section{Discussion}

This study provides the first detailed evidence of elevated temperatures in both leaves and inflorescences in sub-Antarctic megaherb species. All measured species showed a heating response that could be related to either ambient air temperature or PAR levels, but the heating response varied among species and plant structures.

Heating of leaves and inflorescences can be affected by a range of interacting factors, including both physiological and morphological plant traits. Heating through physiological processes is, for instance, documented from tropical regions, where thermogenesis heats reproductive parts of the plant, such as in Rafflesiaceae (Patino et al. 2002), Araceae (Meeuse \& Raskin 1988) and several other angiosperm families. Our results indicate however that thermogenesis is not occurring in sub-Antarctic megaherbs, as plant temperatures overall were closely related to air temperatures. Rather, we suggest that certain morphological vegetative and floral traits in combination with ambient temperature and PAR levels are the cause of the heating observed.

\section{Links among plant morphology, air temperature and PAR}

Four of the six investigated species had hairy leaves (Table 1). The hairy leaves of Pleurophyllum species, especially the large, corrugated leaves of $P$. speciosum, were very warm compared to background vegetation, and species with hairy leaves showed greater heating than the more glabrous leaved species Bulbinella rossii and Anisotome latifolia. Hairiness is shown to protect against both high and low temperature extremes in tropical alpine regions (Miller 1986). Overheating is avoided by the fact that hairiness can create silvery, shiny surfaces that increase the reflectance (Bliss 1962). On the other hand, hairy leaves can contribute to heating as the hairs reflect long wave radiation within the boundary layer (Rundel et al. 1994). Such heat reflection within the boundary layers is, for instance, common in giant rosette species in the tropics (Rundel et al. 1994). In the cool, sub-Antarctic, cloudy climate, megaherbs are not likely to be threatened by overheating. Hairiness in sub-Antarctic megaherbs has probably not enhanced survival through an increase in albedo. The time-course measurements in $P$. speciosum showed in fact the greatest temperature increase was during high PAR levels, and this species had the hairiest leaves of the species included in this study (Allan 1982). Pleurophyllum hookeri has densely hairy leaves, and although not studied in detail here, there is evidence to suggest that heating of the leaves, due to hairiness, contributes to survival in harsh environments (Jenkin \& Ashton 1979). Taken together, our results suggest that hairy leaves in sub-Antarctic megaherbs enhance internal heat reflection within the boundary layers.

Plant architecture may also influence boundary layers and heating. Prior to our work, Wardle (1991) reported leaf temperatures for P. speciosum that ranged from 20 to $25^{\circ} \mathrm{C}$ and suggested that the large leaves of this species may form a "greenhouse space," which could be beneficial for metabolic and reproductive processes under cool, sub-Antarctic conditions. Our results for P. speciosum correspond to the leaf temperatures given by Wardle (1991), but also provide the first evidence of significant thermal patterning in this species in relation to plant architecture. In the thermal images of $P$. speciosum, the combined effects of hairs and corrugated leaf surfaces can be seen very clearly; the leaves are covered with long, protruding hair at the ridges of individual leaf corrugations, which are warmer than the base of the corrugations (Fig. la). Our results imply that leaf properties that affect boundary layers and convective cooling appear to be correlated with rapid heating of the leaf. In $P$. speciosum, these elevated leaf temperatures persist for many minutes after a sunny period has passed (Fig. la) but do not persist into the night (data not shown).

Pleurophyllum speciosum also showed striking patterns of floral heating related to floral structure. The densely packed, dark purple disc florets were observed to be much warmer than the loosely arrayed, lighter purple ray florets. This result supports Dietrich \& Körner's (2014) observation that dense Asteraceae structures are particularly efficient at heating under solar radiation. In addition, this species has the deepest coloured inflorescences of all megaherb species, with very dark purple pigmented inflorescences that show the so-called 
Ageratum effect: anomalous reflectance due to some pigments reflecting infra-red light that is picked up as red by a camera (Eckert 2004). This dark pigmentation explains the strong response to PAR rather than ambient air temperature in P. speciosum. The heating of the inflorescence is therefore generated by the combination of the dark purple disc florets that absorb radiation and the densely packed structure of the capitulum that retains heat. Other studies in cold climates have also proven strong links between solar radiation and floral heating (Kevan 1975; Young 1984; Dietrich \& Körner 2014).

In spite of hairiness and architecture that increase heating of leaves, the inflorescences of both P. speciosum and $P$. criniferum were often warmer than their leaves, while there was little difference between leaf and inflorescence temperature for $B$. rossii and Stilbocarpa polaris. This difference can be related to the effect of pigmentation; both P. speciosum and P. criniferum have darker flowers than B. rossii and S. polaris.

Interestingly, both leaves and inflorescences of $S$. polaris showed an almost identical increase in temperature with increasing PAR. Dietrich \& Körner (2014) found that flowering units were around $3{ }^{\circ} \mathrm{C}$ warmer than foliage $\left(6^{\circ} \mathrm{C}\right.$ above air temperature), with the exception of flowers from cushion plants, which were cooler than the background vegetation. The floral display of $S$. polaris was situated within the large, elliptical, sparsely hairy leaves, where the inflorescences are likely to benefit from the shelter provided by the large, corrugated leaves, resulting in similar heating effects between inflorescence and leaves.

Bulbinella rossii showed the smallest heating response. This species has smooth leaves, and a brush-like inflorescence structure that allows some airflow between the flowers. Still, the inflorescences were somewhat warmer than ambient air, and it was observed that most heating occurred around the youngest, newly opened flowers in the inflorescence (Fig. 1d). The greenish-yellow colour of the inflorescences of $B$. rossii is unlikely to contribute much towards heating the inflorescence (McKee \& Richards 1998). However, the flower buds, and newly opened flowers, were more densely arrayed than older flowers, which may explain higher heat retention in the younger part of the inflorescence. Young flowers also produce the most nectar (Lord et al. 2013), and heating in this area may be involved in pollinator attraction, as warm flowers attract cold climate insects by offering them a heat reward (Cooley 1995; Dyer et al. 2006). Floral visitors have been observed on $B$. rossii during cold and windy conditions (Lord et al. 2013), and we consider it likely that floral visitors are taking advantage of the warmth provided by the inflorescence, as has been seen in other cold climates (Kevan 1972).

Our sample size was limited, which makes it difficult to assert definitive functional connections between the environmental variables, plant structures and plant responses. Increasing the sample size for each species would be beneficial to evaluate the robustness of our results. In particular, the PAR data exhibit a relatively small range of variation. It is possible that the thermal responses of leaves and flowers could vary from what was found in this study if further data collection was undertaken, as PAR levels range widely from day to day, and between morning and afternoon, and these data represent single-day measurements taken mostly from midday to afternoon. For instance, very high PAR levels are not always related to further increased heating; the sub-Antarctic plant Pringlea antiscorbutica shows low dependence on ambient temperature for photosynthesis, but is very sensitive to PAR values (Aubert et al. 1999). Under high PAR levels, the photosynthesis rate in $P$. antiscorbutica can increase the transpiration rate to such an extent that the leaf temperature remains lower than ambient temperature (Hennion et al. 2006).

\section{Possible convergent evolution of megaherbs}

The megaherb growth form, which has evolved across different sub-Antarctic plant species (Mitchell et al. 1999), may be an example of convergent evolution. Sub-Antarctic megaherbs possess similar leaf and growth form traits that have been identified by Reich et al. (1999) in other giant herbaceous species across six biomes. These include giant Lobelia species, Senecio species and Rheum nobile; all exhibit giant growth forms with accompanying traits such as hairs which are shown to provide mini-"glasshouse" effects (Meinzer et al. 1994; Omori et al. 2000; Antonelli 2009).

Cloud cover is almost constant in the sub-Antarctic and is common in the tropical mountainous regions near the equator, so this condition is similar in the two regions (Rundel et al. 1994; Loope \& Giambelluca 1998). However, gigantism and hairy structures in tropical alpine herbs are usually not related to cloud cover but is considered to confer a benefit via the high thermal inertia of massive structures and the insulating properties of hairs, reducing diurnal temperature extremes (Miller 1986; Meinzer et al. 1994). Megaherbs in the subAntarctic regions do not experience temperature extremes, but are rather faced with an isothermal, relentlessly cool, windy environment with few, unpredictable sunny periods. Regardless, selection for adaptations that conserve heat, increase boundary layers and protect 
vulnerable growing shoot and floral buds is still likely to be important (Troll 1960; Rundel et al. 1994). Our results suggest that temperature fluctuations per se are not necessarily the driving factor behind plant gigantism in cold climates; rather, the overall advantage of these adaptations is to maximize heat gain during the short, unpredictable periods of clear sky and high PAR, and to increase the efficiency of metabolic processes. We propose that despite the strikingly, geographically different, environments of the sub-Antarctic and the tropical alpine regions, cool annual temperatures have selected for the same adaptations in order to maximize available solar radiation resources, leading to convergent evolution.

\section{Conclusion}

Thermal benefits are vital for reproduction, metabolism and growth of plants that inhabit the consistently cool, windy conditions of the sub-Antarctic region. Leaf hairiness, inflorescence colour and shape are all factors which can contribute to heating in response to solar radiation in sub-Antarctic megaherbs, in a remarkably similar manner to those traits seen in tropical alpine giant herbs. We suggest this similarity is most likely a result of convergent evolution in response to limited net energy inputs.

\section{Acknowledgements}

We thank the New Zealand Department of Conservation, South and Eastern South Island Region, for permits and logistic support on Campbell Island; Henk Haazen, Captain of Tiama and Captain and crew of HMNZS Otago for transport; Vickey Tomlinson and Lynne Huggins for help in the field; Chris Cornwall for commenting on the manuscript. We acknowledge the University of Otago Maori Doctoral Scholarship for financial support. All thermal image and probe data, environmental measurements and thermal information are archived in the PANGAEA information system, an Open Access library aimed at archiving, publishing and distributing georeferenced data from earth system research (https://doi.pangaea. de/10.1594/PANGAEA.862013).

\section{References}

Allan H.H. 1982. Flora of New Zealand. Vol. 1. Wellington: P. Hasselberg, Government Printer.

Antonelli A. 2009. Have giant lobelias evolved several times independently? Life form shifts and historical biogeography of the cosmopolitan and highly diverse subfamily Lobelioideae (Campanulaceae). BMC Biology 7, article no. 82, doi: http://dx. doi.org/10.1186/1741-7007-7-82.
Aubert S., Assardi N., Boutin J., Frenot Y. \& Dorne A. 1999. Carbon metabolism in the Subantarctic Kerguelen cabbage Pringlea antiscorbutica R. Br.: environmental controls over carbohydrates and proline contents and relation to phenology. Plant, Cell and Environment 22, 243-254.

Bergstrom D.M. \& Chown S.L. 1999. Life at the front: history, ecology and change on southern ocean islands. Trends in Ecology $\theta$ Evolution 14, 472-477.

Billings W.D. \& Mooney H.A. 1968. The ecology of Arctic and alpine plants. Biological Reviews 43, 481-529.

Bingham R.A. \& Ort A.R. 1998. Efficient pollination of alpine plants. Nature 391, 238-239.

Bliss L.C. 1962. Adaptations of Arctic and alpine plants to environment conditions. Arctic 15, 117-144.

Chapin F.S. III \& Körner C. 1995. Arctic and alpine biodiversity. Berlin: Springer.

Choler P. 2005. Consistent shifts in alpine plant traits along a mesotopographical gradient. Arctic Antarctic and Alpine Research 37, 444-453.

Cooley J.R. 1995. Floral heat rewards and direct benefits to insect pollinators. Annals of the Entomological Society of America 88, 576-579.

Dietrich L. \& Körner C. 2014. Thermal imaging reveals massive heat accumulation in flowers across a broad spectrum of alpine taxa. Alpine Botany 124, 27-35.

Dyer A., Whitney H.M., Arnold S., Glover B.J. \& Chittka L. 2006. Bees associate warmth with floral colour. Nature 442 , 525.

Eckert M. 2004. Final report on the project. Developing a technique for obtaining colour accurate photographs of Australian native flowers. Accessed on the internet at http:// www.aff.org.au/AFF3_Res_repts.htm\#G_67 on 9 May 2016.

Givnish T. 2010. Giant lobelias exemplify convergent evolution. BMC Biology 8, article no. 3, doi: http://dx.doi.org/10. 1186/1741-7007-8-3.

Halloy S.R.P. \& Mark A.F. 1996. Comparative leaf morphology spectra of plant communities in New Zealand, the Andes and the European Alps. Journal of the Royal Society of New Zealand 26, 41-78.

Hedberg I. \& Hedberg O. 1979. Tropical-alpine life-forms of vascular plants. Oikos 33, 297-307.

Hennion F., Huiskes A.H.L., Robinson S. \& Convey P. 2006. Physiological traits of organisms in a changing environment. In D.M. Bergstrom et al. (eds.): Trends in Antarctic terrestrial and limnetic ecosystems: Antarctica as a global indicator. Pp. 129159. Berlin: Springer.

Jenkin J.F. \& Ashton D.H. 1979. Pattern in Pleurophyllum herbfields on Macquarie Island (Subantarctic). Australian Journal of Botany 4, 47-66.

Kevan P.G. 1972. Insect pollination of High Arctic flowers. Journal of Ecology 60, 831-847.

Kevan P.G. 1975. Sun-tracking solar furnaces in High Arctic flowers-significance for pollination and insects. Science 189, 723-726.

Körner C. 2003. Alpine plant life: functional plant ecology of high mountain ecosystems. Berlin: Springer. 
Loope L. \& Giambelluca T.W. 1998. Vulnerability of island tropical montane cloud forests to climate change, with special reference to East Maui, Hawaii. Climatic Change 39, 503-517.

Lord J.M., Huggins L., Little L.M. \& Tomlinson V.R. 2013. Floral biology and flower visitors on Subantarctic Campbell Island. New Zealand Journal of Botany 51, 168-180.

Mark A.F., Dickinson K.J.M. \& Hofstede R.G.M. 2000. Alpine vegetation, plant distribution, life forms, and environments in a perhumid New Zealand region: oceanic and tropical high mountain affinities. Arctic Antarctic and Alpine Research $32,240-254$.

McKee J. \& Richards A.J. 1998. Effect of flower structure and flower colour on intrafloral warming and pollen germination and pollen-tube growth in winter flowering Crocus L. (Iridaceae). Botanical Journal of the Linnean Society 128, 369-384.

Meeuse B.J. \& Raskin I. 1988. Sexual reproduction in the arum lily family, with emphasis on thermogenicity. Sexual Plant Reproduction 1, 3-15.

Meinzer F. \& Goldstein G. 1985. Some consequences of leaf pubescence in the Andean giant rosette plant Espeletia timotensis. Ecology 66, 512-520.

Meinzer F., Goldstein G. \& Rada F. 1994. Páramo microclimate and leaf thermal balance of Andean giant rosette plants. In P.W. Rundel et al. (eds.): Tropical alpine environment: plant form and function. Pp. 45-59. Cambridge: Cambridge University Press.

Meurk C.D., Foggo M.N., Thomson B.M., Bathurst J. \& Crompton M.B. 1994. Ion-rich precipitation and vegetation pattern on Subantarctic Campbell Island. Arctic and Alpine Research 26, 281-289.

Meurk C.D., Foggo M.N. \& Wilson J.B. 1994. The vegetation of Subantarctic Campbell Island. New Zealand Journal of Botany 18, 123-168.

Miller G. 1986. Pubescence, floral temperature and fecundity in species of Puya (Bromeliaceae) in the Ecuadorian Andes. Oecologia 70, 155-160.

Mitchell A.D., Meurk C.D. \& \&Wagstaff S.J. 1999. Evolution of Stilbocarpa, a megaherb from New Zealand's sub-Antarctic islands. New Zealand Journal of Botany 37, 205-211.

Monteith J. \& Unsworth M. 2013. Principles of environmental physics. Plants, animals and the atmosphere. 4th edn. Oxford: Academic Press.

Moore L.B. \& Edgar E. 1976. Flora of New Zealand. Vol. 2. Wellington: Government Printer.

Nicholls V.J. \& Rapson G.L. 1999. Short communication: biomass allocation in Subantarctic megaherbs, Pleurophyllum speciosum (Asteraceae) and Anisotome latifolia (Apiaceae). New Zealand Journal of Ecology 23, 87-93.

Omori Y., Takayama H. \& Ohba H. 2000. Selective light transmittance of translucent bracts in the Himalayan giant glasshouse plant Rheum nobile Hook.f. \& Thomson (Polygonaceae). Botanical Journal of the Linnean Society 132, 19-27.

Patino S., Aalto T., Edwards A.A. \& Grace J. 2002. Is Rafflesia an endothermic flower? New Phytologist 154, 429-437.

Peat N. 2006. Subantarctic New Zealand: a rare heritage. Wellington: Department of Conservation.

Pendlebury S.F. \& Barnes-Keoghan I.P. 2007. Climate and climate change in the sub-Antarctic. Papers and Proceedings of the Royal Society of Tasmania 141, 67-82.

Reich P.B., Ellsworth D.S., Walters M.B., Vose J.M., Gresham C., Volin J. \& Bowman W. 1999. Generality of leaf trait relationships: a test across six biomes. Ecology 80, 1955-1969.

Reich P.B., Walters M.B. \& Ellsworth D.S. 1997. From tropics to tundra: global convergence in plant functioning. Proceedings of the National Academy of Sciences of the United States of America 94, 13730-13734.

Rejskova A., Brom J., Pokorny J. \& Korecko J. 2010. Temperature distribution in light-coloured flowers and inflorescences of early spring temperate species measured by Infrared camera. Flora 205, 282-289.

Rundel P.W., Smith A. \& Meinzer F. 1994. Tropical alpine environments: plant form and function. Cambridge: Cambridge University Press.

Smith A.P. \& Young T.P. 1987. Tropical alpine plant ecology. Annual Review of Ecology and Systematics 18, 137-158.

Song B., Zhang Z., Stocklin J., Yang Y., Niu Y., Chen J. \& Sun H. 2013. Multifunctional bracts enhance plant fitness during flowering and seed development in Rheum nobile (Polygonaceae), a giant herb endemic to the high Himalayas. Oecologia 172, 359-370.

Troll C. 1960. The relationship between the climates, ecology and plant geography of the tropical high mountains. Proceedings of the Royal Society Series B 152, 529-532.

UNESCO. 1992-2014. New Zealand Sub-Antarctic Islands. United Nations Educational, Scientific and Cultural Organization. Accessed online at http://whc.unesco.org/en/list/877 in June 2015.

Wagstaff S.J., Breitwieser I. \& Ito M. 2011. Evolution and biogeography of Pleurophyllum (Astereae, Asteraceae), a small genus of megaherbs endemic to the Subantarctic Islands. American Journal of Botany 98, 62-75.

Wardle D. 1991. The vegetation of New Zealand. Cambridge: Cambridge University Press.

Weijers S., Wagner-Cremer F., Sass-Klaassen U., Broekman R. \& Rozema J. 2013. Reconstructing High Arctic growing season intensity from shoot length growth of a dwarf shrub. Holocene 23, 721-731.

Yang Y., Körner C. \& Sun H. 2008. The ecological significance of pubescence in Saussurea medusa, a high-elevation Himalyan "woolly plant." Arctic, Antarctic and Alpine Research 40, 250-255.

Young T.P. 1984. Solar irradiation increases floral development rates in Afro-alpine Lobelia telekii. Biotropica 16, 243-245. 